\title{
Estudo epidemiológico de tracoma
}

\author{
Epidemiological study of trachoma
}

Ricardo Mörschbächer ${ }^{1}$, Norma Helen Medina ${ }^{2}$, Expedito J. A. Luna ${ }^{3}$

Prezado Prof. Dr. Wallace Chamon

Editor dos Arquivos Brasileiros de Oftalmologia

Causou-nos estranheza a publicação do artigo "Tracoma: estudo epidemiológico de escolares em Alagoas - Brasil", publicado nesta revista (Arq. Bras. Oftalmol. 2009;72(3):355-9(1). Participamos ativamente de todo processo de realização do Inquérito Nacional para Prevalência do Tracoma, promovido pelo Ministério da Saúde, assim como centenas de outros profissionais, e sabemos da grande logística, quantidade de pessoas envolvidas e recursos financeiros gastos para que em cada estado deste país fosse realizado tal trabalho.

A concepção do projeto do inquérito epidemiológico nacional de tracoma em escolares foi de responsabilidade da equipe do Programa Nacional de Controle do Tracoma (PNCT) do Ministério da Saúde, especificamente das Dras. Maria de Fátima Lopes e Helen Selma Freitas, em conjunto ao Dr. Expedito Luna, então diretor do Departamento de Vigilância Epidemiológica do Ministério da Saúde, ao qual se vinculava o PNCT, e a Dra. Norma Helen Medina, consultora do PNCT. O desenvolvimento do plano amostral foi realizado pela Dra. Maria Regina Cardoso, do Departamento de Epidemiologia da Faculdade de Saúde Pública da USP, uma das principais especialistas em amostragem em estudos no campo da saúde do Brasil, com a colaboração da Dra. Inês Kazue Koizumi e da Sra. Neusa Bernardes. A execução dos trabalhos de campo foi coordenada pelas Dras. Lopes e Freitas, e pelo Dr. José Alfredo Guimarães, também da equipe do PNCT, à época.

\section{SOBRE O INQUÉRITO NACIONAL DE PREVALÊNCIA DE TRACOMA - BRASIL}

Durante o período de 2002 a 2008, o Ministério da Saúde promoveu um inquérito nacional de prevalência de tracoma em escolares, com objetivo de conhecer a ocorrência e distribuição deste agravo no país.

Para a realização deste inquérito, o tamanho da amostra em cada Estado foi determinado, considerando uma prevalência de 5\% de tracoma em todas as suas formas clínicas, aceitando-se um erro máximo de amostragem de 0,01 em 95\% das possíveis amostras e o acréscimo de $20 \%$. A amostra foi de 7.200 escolares, da $1^{\underline{a}}$ a $4^{\underline{a}}$ séries do ensino fundamental, selecionada de forma aleatória e por conglomerados e constituída de 3 estratos populacionais (municípios grandes, intermediários e menores).

Participaram do estudo somente os municípios com IDH - M menor que a média nacional $(0,764)$. Foi realizado cálculo da média de alunos por escola para estimar o tamanho adequado das unidades primárias de amostragem (UPA). O sorteio foi realizado iniciando com um número aleatório e somando-se o intervalo de amostragem. As UPAS sorteadas aleatoriamente correspondiam a alunos de uma escola de um determinado município.

Foram utilizados dados do Censo de Escolares, dos bancos mais recentes do Ministério da Educação (MEC), dados populacionais do IBGE e do Fundo das Nações Unidas para Desenvolvimento - PNUD, para os Índices de Desenvolvimento Humano Municipal - IDH-M.

Todos os indivíduos selecionados para a amostra foram examinados para detecção de casos de tracoma, segundo critério de diagnóstico da Organização Mundial de Saúde (OMS).

O inquérito nacional iniciou no final do ano 2002 e finalizou a última etapa estadual no ano de 2008. Os dados finais do inquérito nacional ainda não foram oficialmente publicados porque alguns bancos foram redigitados e no momento encontra-se em consolidação final, ajustes, estudo de efeito do desenho, para publicação. A Dra. Maria de Fátima Lopes apresentou os resultados preliminares do inquérito no Congresso Brasileiro de Prevenção de Cegueira, em Florianópolis, em 2008, tendo sido agraciada com o prêmio Conselho Brasileiro de Oftalmologia.

\section{SOBRE O INQUÉRITO NACIONAL DE PREVALÊNCIA DE tRACOMA - ETAPa Alagoas}

No ano de 2004 ocorreu a etapa estadual do inquérito de prevalência de tracoma em Alagoas, coordenado pela Secretaria da Saúde do Estado de Alagoas - SES/AL.

O Ministério da Saúde (MS) em parceria com a SES/AL promoveu a capacitação dos técnicos do estado, em agosto/setembro de 2004, com objetivo de operacionalizar as atividades de campo. Foram treinados em torno de 20 profissionais da SES/AL, nesta capacitação, com funções de entrevistadores.

Os exames de detecção do tracoma nos escolares selecionados foram realizados por profissionais de várias Secretarias Estaduais de Saúde e Coordenações Regionais da Funasa dos Estados de Sergipe, Paraíba, Pernambuco, Rio Grande do Norte e um médico oftalmologista do Estado de São Paulo. Na época o Estado de Alagoas tinha apenas três pessoas padronizadas, pelo Ministério da Saúde, para diagnóstico de tracoma, de acordo com as normas da Organização Mundial de Saúde e, infelizmente, nenhum destes três técnicos pôde participar da etapa de campo do referido inquérito. 
Os dados coletados em campo por equipe de examinadores com experiência de no mínimo três anos de trabalho de campo, foram registrados em fichas padronizadas encaminhados, a pedido da SES/AL (que não tinha digitadores disponíveis no momento) para - Ministério da Saúde, que digitou o banco de dados final do inquérito do Estado. No banco final foram realizados procedimentos de limpeza de dados, revisão da digitação e exclusão e/ou inclusão de registros, de acordo com os registros das planilhas recebidas.

Após a conclusão da etapa de campo a SES/AL consolidou os dados coletados em um texto em "mimeo" onde relata a ocorrência do inquérito de tracoma no estado e divulga os dados e o resultado, em um documento intitulado "Inquérito Epidemiológico Nacional sobre tracoma Perfil Alagoas", redigido e divulgado no Estado de Alagoas em 2005.

\section{SOBRE A PUBLICAÇÃO DE ARTIGO INTITULADO "TRACOMA: ESTUDO EPIDEMIOLÓGICO DE ESCOLARES em Alagoas - Brasil" nos Arquivos Brasileiros de Oftalmologia, no ano 2009}

No ano de 2009, foi publicado pelos Arquivos Brasileiros de Oftalmologia um artigo intitulado "Tracoma: estudo epidemioló- gico de escolares em Alagoas - Brasil" (Arq. Bras. Oftalmol. 2009; 72(3):355-9)(1), que relata um estudo desenvolvido na mesma ocasião, nos mesmos municípios e com a mesma metodologia. Segundo o texto do manuscrito, o trabalho teria sido realizado por "graduandos" da Faculdade de Medicina sob supervisão de "professores" do Departamento de Oftalmologia da Universidade Federal de Alagoas. No entanto, à época da realização do estudo, a SES/AL não havia conseguido articular a integração com as universidades de Alagoas.

Portanto, concluímos que os dados utilizados no artigo publicado pelos Arquivos Brasileiros de Oftalmologia nada mais são do que os dados levantados pelo Inquérito Nacional de Prevalência de Tracoma em Escolares do Ministério da Saúde, que foram indevidamente apropriados, sem dar os devidos créditos a instituição que realmente fez o trabalho, e sem autorização de parte dos responsáveis do ministério da saúde.

\section{REFERÊNCIAS}

1. Damasceno RW, Santos RR, Cavalcanti TR, Hida RY, Santos MJ, Santos AM, et al. Tracoma: estudo epidemiológico de escolares em Alagoas - Brasil. Arq Bras Oftalmol. 2009;72(3):355-9.

\footnotetext{
Assessor do Ministério da Saúde/Tracoma. Professor Universidade Federal das Ciências da Saúde de Porto Alegre (RS), Brasil.

${ }^{2}$ Assessor do Ministério da Saúde/Tracoma. Centro de Oftalmologia Sanitária da Secretaria de

Estado da Saúde de São Paulo (SP), Brasil.

${ }_{3}^{3}$ Professor do Instituto de Medicina Tropical da Universidade de São Paulo (SP), Brasil.
} 